\title{
A Decision-Making Framework for Sustainable Supply Chain Finance in Post-COVID Era
}

\author{
Nainsi Gupta ${ }^{1}$ (D) Gunjan Soni ${ }^{1}[$
}

Received: 21 January 2021 / Accepted: 29 June 2021 / Published online: 14 July 2021

(c) Global Institute of Flexible Systems Management 2021

\begin{abstract}
COVID-19 has severely damaged the social values and economic values of global supply chain. This unprecedented pandemic acts as hindrance in the path of sustainable development goals that are to be achieved by 2030. This study focuses on the disruption that has taken place due to COVID outbreak and also identifies the role of sustainable finance in achieving sustainable supply chain. This study highlighted the critical factors that are important to adapt the sustainable supply chain. A case study of food industry has been performed to prioritize the critical factors with the help of MCDM techniques. Major criteria and sub-criteria that play a crucial role in sustainable supply chain finance have been listed here. This study contributes in the area of sustainable supply chain and how finance can play a major role in achieving sustainable supply chain and ultimately sustainable development goals. The findings of this study show that social values of any industry are the most crucial asset for any organization.
\end{abstract}

Keywords Sustainable supply chain finance $\cdot$ AHP $\cdot$ COVID-19 $\cdot$ Sustainable finance

\section{Introduction}

Global supply chains have been drastically damaged due to COVID-19. COVID-19 is an unprecedented disaster that not only affected supply chains economically but also impacted the social values and responsibility of organizations. Global and local organizations are severely affected by this economic downturn due to Coronavirus outbreak. Gross domestic product (GDP) of the world drop by $4.2 \%$ only because of this COVID outbreak (OCED, 2021), which not only severely impact the economy but all other issues that are counter results of such economic downturn such as increasing poverty, unemployment, hunger, inequality, etc. More than 4 million people in India have lost their jobs due to COVID while 81 million people lost their jobs in Asia Pacific labor markets as per International Labour Organization (ILO, 2021). Out of 500 top companies of Fortune, $94 \%$ of the companies have been severely impacted due to

Gunjan Soni

gsoni.mech@mnit.ac.in

Nainsi Gupta

nainsigupta8@gmail.com

1 Department of Mechanical Engineering, Malviya National Institute of Technology, Jaipur, India
COVID (Fortune, 2020). This crisis has uncovered the vulnerabilities of the supply chain and proved that no one is immune, either it is government or business organizations or social policies or international policies or individual as well.

United Nations Sustainable development Goals (SDGs) that are to be achieved by 2030 may face some delay due to COVID (Filho et al. 2020).As per Runde et al. (2020), Filho et al.(2020), COVID make it difficult to implement the 17 SDGs but increased their importance for maintaining progress as compared to Pre-COVID. Figure 1 highlights the SDGs that are being restricted due to COVID-19. Caldecott (2020), Sharma et al. (2020) highlighted that recovery efforts of COVID may transition the world toward more sustainable goals as compared to Pre-COVID. This transition will not only help to recover supply chains but also help to become more resilient for further disruptions. Cardenas et al. (2020) discussed Post-COVID recovery and explained that these efforts are less about getting back to old normal, but more about being adaptive with uncertainties. This crisis is not just a call to change the business decisions but also a call to change the way of life.

Sustainable development (SD) is defined as development that "meets the needs of the present without compromising the ability of future generations to meet their own needs" (Brundtland, 1987). SD owns intricacy, dynamism, and 


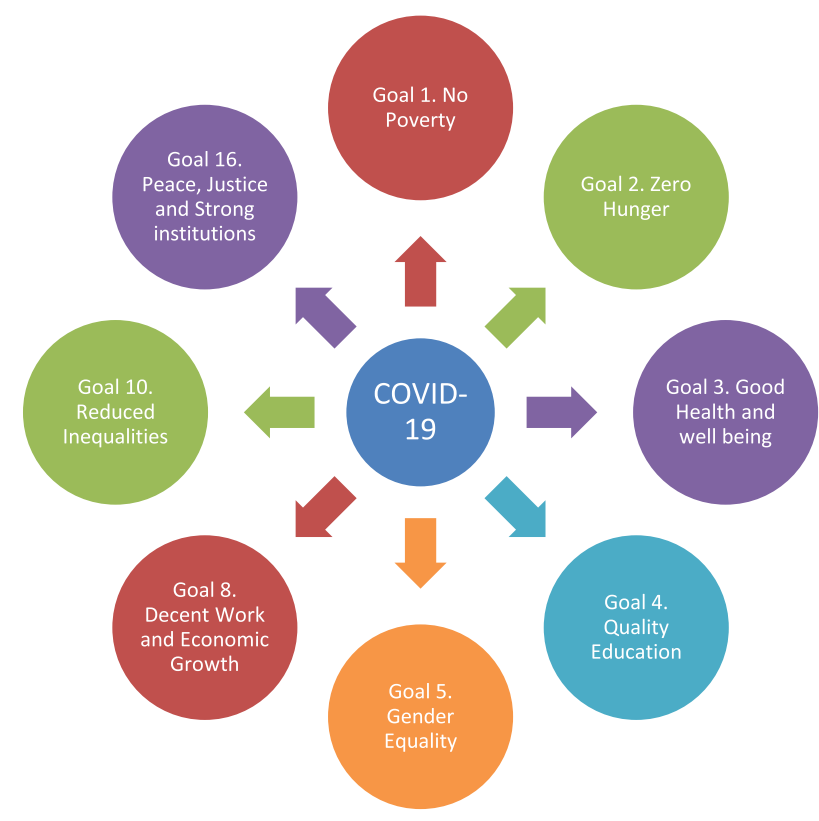

Fig. 1 Main impacts of COVID-19 on sustainable development goals (Source: Filho et al., 2020)

unpredictability that exists in financial and human activities. This multifaceted nature is showed through collaborations between the social perspectives, for example, organizations and projects, and the environmental viewpoints, every one of which has advancing properties that together make the world out of SD (Tseng et al., 2018). COVID has severely impacted the economic and societal goals of SD. COVIDrecovery efforts may stimulate the need for sustainable finance because to achieve the objectives of Paris Agreement and United Nations SDGs, finance and financial services must be provided in a way to support, enable and encourage the organizations at a local and global level to achieve these objectives (Caldecott, 2020). During the current pandemic, companies have had the chance to rethink their local as well as global supply chain strategy and accelerate toward adaption of long-terms sustainable goals for managing future challenges (Karmaker et al., 2020). Financial and nonfinancial support from government and other supply chain partners can help to boost sustainability process and develop a resilient supply chain. Sustainable supply chain finance (SSCF) helps to set up a connection and establish stability among triple bottom line (TBL) aspects (i.e., economic, social, and environmental).

This study is being performed to identify the prominent factors that may play an important role in sustainable supply chain finance (SSCF). Supply chain finance refers to "the solutions provided by financial institutions and fintech companies that integrate cash flow with product and information flows along the supply chain to ensure cash-flow optimization from SC-perspective" (Jia et al., 2019). SSCF assist in developing an efficient flow of finance throughout the supply chain that simultaneously considers social and environmental issues (Tseng et al. 2019a; b).

This study focuses on the need for SSCF in the context of food supply chains to recover them from the long-term impacts due to COVID and transition toward SDGs to make them more resilient for further disaster. Here, we have identified the most critical factors that play an important role in SSCF especially for the organizations that are looking for long-term business benefits, not only in terms of revenues but also increase their social values and environmental policies.

The study is organized in the following ways: (1) literature review that discusses the opinions of authors regarding the role of SSCF in Post-COVID and the critical factors. (2) Methodology, which focuses on the Fuzzy-AHP technique that we are going to use to identify the most critical factors, (3) case study of a local food industry, (4) results, (5) discussion, (6) conclusion.

\section{Literature Review}

This section gives an overview of sustainable development, sustainable finance and SSCF and methodology. Here, we will also discuss about the transition toward sustainable goals in Post-COVID, based on the facts of literature.

\section{Sustainable Development}

The main goal of Sustainable development is to improve resilience and adaptability (Barrow 2018). Agrawal et al. (2021) discussed how sustainable innovation can help the firms to become competitive in market. Schoenmaker (2019) highlights the challenges of sustainable development that are economic, social, and environmental; and also ranked them as environmental challenges as the essentials to serve as a livable planet; next social challenges that are important due to well-connected society that can organize production and consumption to bring prosperity; and finally economic challenges that are cohesive result of both the above challenges.

Barrow (2018) also describe sustainable development belongs to three goals, i.e., economic, social, and environmental. As per this study, sustainable development is basically optimization of natural resources without breakdown of environment and maximizes human well-being. Sustainable development requires efficient prediction of threats; vulnerability monitoring and assessing; identify limitations and opportunities to mitigate problems; and enhance adaptation.

Sustainable development features the advancement of values and practices that are consistent with the company's standards, and it includes instructing and finding out about the idea of sustainable development for stakeholders 
(Tseng et al. 2018). This study also focuses on the proactive approach of sustainable development for competitiveness, economic advantages, and community social responsibility.

United Nations approved 17 sustainable development goals in 2015, to be achieved in 2030. These goals focus on all the issues related with sustainable development (Schoenmaker, 2019). Filho et al. (2020) discusses how COVID-19 has increased the importance of sustainable development. This study highlights the transition of economy toward sustainability.

\section{Sustainable Finance}

Traditional Finance is basically considered as strategic decisions that assist the top management. This focuses on maximizing the financial return along with profitability of shareholders. While sustainable finance aims to maximize the value creation of the organization along with profitability of all the stakeholders. Sustainable finance is considered as allocation of funding to its most productive use that not only focuses on economic returns but also cares for environmental and social goals of the organization. The evolution of sustainable finance highlights the wide classification from 'economic' to 'economic, societal and environmental' considerations (Schoenmaker, 2019). Arulraj and Annamalai (2020) described the importance of finance allocation along with finance. They described how proper allocation of finance in any organization may lead to increase in productivity.

Ferreira (2016) discusses the relationship between finance and sustainability; and describe how finance can play an important role in achieving sustainable development goals. As per this study, finance can suggest an appropriate functioning of the environment and the society in which the financial framework works.

\section{Sustainable Supply Chain Finance}

Jia et al. (2019) discusses the growing interest of supply chain finance for improving supply chain sustainability. Business for Social Responsibility (BSR), a non-advantageous organization in US that has specialization in corporate sustainability, proposed the term sustainable supply chain finance (SSCF) in June 2018, disclosing extensive opportunities and worth with this concept. According to BSR, SSCF is defined as:

"Supply chain finance practices and techniques that support trade transactions, in a manner that minimizes negative impacts and creates environmental, social, and economic benefits for all stakeholders involved in bringing products and services to the market." (Jia et al., 2019).

This concept has promoted the role of supply chain finance in sustainability improvement (Jia et al., 2019; Tseng et al., 2018). SSCF alludes to imaginative SCF arrangements that can both boost the sustainable performance of suppliers or potentially retailers, along these lines encouraging the empowering agents and alleviating boundaries toward sustainable SCM practice, and thus improve the sustainable performance of the whole supply network (Tseng et al., 2018).

Silvestre (2015) discusses sustainable supply chain as a closed loop that incorporates learning and innovation to meet sustainable supply chain goals along with the trajectories that may be followed. Mani et al. (2018) discusses the social perspective of supply chain sustainability and highlights the sustainability adoption in 50+ companies. This study highlights the social issues that are present in the organization along with which sector has more contribution in the same.

Abdel-Basset et al. (2020) performed a study that evaluates the performance measures that provide SSCF in the gas industry under uncertainty. This study identified the most crucial metrics for enhancing firm's performance with the help of MCDM techniques.

Karmaker et al. (2020), performed a study that contributes sustainable supply chain finance in the context of COVID-19. This study investigates the metrics of sustainable supply chain to address supply chain disruptions under the pressure of pandemic. This study reveals the finance role in achieving sustainable supply chain while recovering a shock of COVID-19.

In this study, we are going to perform a case study of food industry that faced financial crisis during COVID-19 and proceeding to transition their supply chain toward sustainable goal in terms of long-term benefits. This study has identified critical measures that may play important role in reconfiguring their supply chain toward sustainability.

\section{Fuzzy AHP}

Due to increased competition decision-making is being considered as one of the complex problem. Researchers and management are looking for various systematic and comprehensive methodologies to provide optimum results. In literature various approach like ANP, VIKOR, AHP, GRA, TOPSIS, DEA, etc. along with their integrated models in different context of problem. These all models have their own significance and limitations.

Here we are going to use Fuzzy-AHP, to prioritize the critical factors related with sustainable SCF. Fuzzy-AHP is a combination of fuzzy and AHP (analytical hierarchy process). AHP is one of the most common methods used in multi-criteria decision-making and was introduced by Saaty (1980). AHP is a methodology that utilizes both the qualitative and quantitative data for decision-making process. Expert suggestion includes qualitative as well as quantitative data that need to be transformed into quantitative figures and 
analyze simultaneously. This method uses expert opinion to find out relative importance of attributes and achieve the optimum solution. But conventional AHP has a limitation to understand human thinking behavior as a precise data/crisp value (Chang 1996). Therefore, fuzzy-AHP has been introduced as an extension of AHP to deal with uncertainty of human responses. Due to variation of linguistic terms from every individual, fuzzy nature plays an important role to find out less risky decisions (Laarhoven and Pedrycz 1983). Fuzzy-AHP approach is used in many areas of decisionmaking like supplier selection, job selection, project selection, etc. This method is one of the most powerful as well as flexible methods to help decision-makers providing precise and best decision when both the qualitative and quantitative factors are to be considered (Biswas et al., 2018).

\section{Methodology}

Fuzzy-AHP model is extension of AHP, used to prioritize the criteria based on expert opinion. Here, we have $\mathrm{n}$ criteria, $F_{1}, F_{2} \ldots, F_{n}$ for which our objective is to estimate the weights of criteria i.e., $w_{1}, w_{2}, \ldots w_{n}$, in such a way that

$$
\sum_{i=1}^{n} w_{i}=1
$$

This is known as normalized weights of all the criteria that help to find out the best solution from the given alternatives. Following steps should be followed to achieve these weights.

Step 1: Hierarchical classification of the given problem by classifying them into criteria and sub-criteria. This step will help to classify the complete problem in the form of hierarchical tree (Fig. 2).

Step 2: Formation of paired comparison matrix based on the opinions of experts. This matrix will show the relative importance of criteria. Here, we will convert linguistic

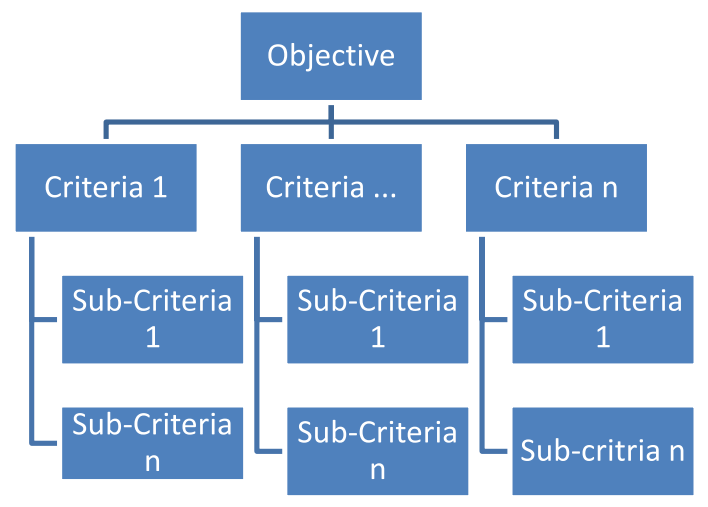

Fig. 2 Hierarchical classification response obtained from the experts into numeric crisp value based on following table:

With the help of above table matrix $A=\left(a_{i j}\right)$ can be obtained, where $a_{i j}$ represents the estimate for relative importance.

$A=\left(a_{i j}\right)=\left[\begin{array}{cccc}a_{11} & a_{12} & \cdots & a_{1 n} \\ \vdots & \vdots & & \vdots \\ a_{n 1} & a_{n 2} & \cdots & a_{n n}\end{array}\right]$

Here, $a_{i j}$ is a reciprocal matrix i.e. $a_{i j} * a_{j i}=1$.

Step 3: In this step, conversion of numeric values in to fuzzy values will be performed. Here, we will use triangular membership function to convert crisp numeric values in to fuzzy numbers with the help of Table 1.

Fuzzy number $N$ on $R$ will be triangular fuzzy number if its membership functions $\left(\mu_{m}\right)$ are equal to following criteria:

$\mu_{m}(x)= \begin{cases}\frac{1}{m-l}-\frac{l}{m-l}, & x \in[l, m] \\ \frac{1}{m-u}-\frac{u}{m-u}, & x \in[m, u] . \\ 0, & \text { otherwise }\end{cases}$

Here $l, m, u$ represents lower, medium, and upper values of triangular fuzzy function (Fig. 3).

Table 1 Conversion of linguistic terms into numeric crisp value

\begin{tabular}{lll}
\hline Linguistic term & Numeric value & $\begin{array}{l}\text { Fuzzy } \\
\text { membership } \\
\text { function }\end{array}$ \\
\hline Equal importance & 1 & $(1,1,1)$ \\
Moderate importance & 3 & $(2,3,5)$ \\
Strong importance & 5 & $(4,5,6)$ \\
Very strong importance & 7 & $(6,7,8)$ \\
Extremely strong importance & 9 & $(9,9,9)$ \\
\hline
\end{tabular}

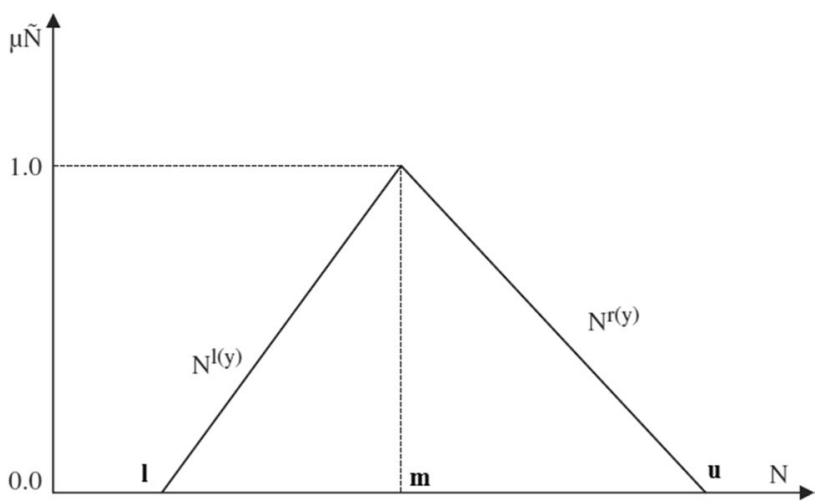

Fig. 3 Triangular membership function 
To convert fraction values in to fuzzy, following equation to be followed

$\tilde{A}^{-1}=(l \cdot m, u)^{-1}=\left\{\frac{1}{u}, \frac{1}{m}, \frac{1}{l}\right\}$.

Step 4: In this step, we will calculate fuzzy geometric mean value $\dot{r}_{i}$ with the help of following equation.

$\dot{r}_{i}=\left(\tilde{A}_{1} \otimes \tilde{A}_{2} \otimes \tilde{A}_{3} \cdots \otimes \tilde{A}_{n}\right)^{1 / n}$,

where, $\left(\tilde{A}_{1} \otimes \tilde{A}_{2}\right)=\left(l_{1}, m_{1}, u_{1}\right) \otimes\left(l_{2}, m_{2}, u_{2}\right)=\left(l_{1} * l_{2}, m_{1} * m_{2}, u_{1} * u_{2}\right)$.

Step 4: Calculation of fuzzy weights can be done as follows:

$\tilde{w}_{i}=\tilde{r}_{i} \otimes\left(\tilde{r}_{1} \oplus \tilde{r}_{2} \oplus \cdots \oplus \tilde{r}_{n}\right)^{-1}$.

Above equation will provide us fuzzy weights for particular criteria. With the help of these fuzzy weights, we can go for selection of best alternative present.

Step 5: To de-fuzzification of the weights obtained from the above step, here we will use of aggregation method used in Awasthi et al. (2018).

$w_{i}=\frac{l+4 * m+u}{6}$

This will give the required weights for all the criteria that help in providing the best solution in decision-making.

\section{Case Study}

The case study has been conducted in local food industry that produces packaged food items. Their supply chain strategy was based on maximizing profit by making efficient supply chain. Their supply chain was basically based on traditional concepts like low-cost labor, cheap raw material, mass production of food items, low-cost packaging and transportation of food products, etc. Before COVID-19 pandemic, they were facing some issue regarding quality or perishability of products, but management try to manage these issues without changing their strategy of supply chain.

This unprecedented pandemic led to major shock for the industry due to their supply chain strategy. The organization face many issues during and after lockdown like unavailability of workers due to their poor economic policies and worker displacement; high amount of wastage due to their bulk purchasing strategy, perishability of food items, uncertainty in demand; change in consumer's food choices, loss of reputation, unavailability of trustworthy suppliers, etc. In short, the industry is at the edge of being bankrupt due to their poor policies and strategies. In Post-COVID, the management has decided to change their strategy from low cost to transparent and sustainable supply chain. This strategy will help them to attract more investors.
The first phase of data collection was performed by interviewing the experts of organization to understand the problem. This stage gave a clear understanding of the problem and important factors that may be important for sustainable supply chain. In the second phase, we identified the important factors that may play an important role in sustainable supply chain finance. The basic criteria and sub-criteria for sustainable supply chain strategies are listed in the following table (Table 2).

In this study, we identified the relative weight of criteria that are related with sustainable supply chain finance by application of Fuzzy-AHP. Here the study was conducted by collecting the responses from experts listed in the following table (Table 3):

With the help of responses collected from the experts, we have analyzed their responses. Following table gives an idea that social values are the most important asset for any organization followed by environmental and economic criteria. Social values includes such as child labor, exploitation of labor, trust issues among stakeholders etc., play a major role in any supply chain (Table 4 ).

Tables 5, 6, 7, and 8 shows the relative importance of environmental, economic, social, and financial criteria that are important to consider while reconfiguring the supply chain. As per Table 5 human rights, data security and exclusion of child labor are one of the most important criteria that every organization must follow because these not only help in achieving sustainability goals but also enhance reputation in market. There are many examples in literature in which companies have to face major disruption only because of their social values.

Table 6 describes inventory control, risk management, and raw material procurement as one of the most important economic criteria. Raw material procurement is the most critical criteria for any particular organization because it leads to around $60-70 \%$ of the shares of the organization capital. Further inventory planning and its management become more critical when considered under uncertain environment. Table 7 highlights the most crucial environmental criteria. According to following table, resiliency of any organization has been allotted the maximum weightage. This describes the ability of any organization to sustain any disruption/shock and recover from that shock as soon as possible. Resiliency of organization has been allotted maximum priority due to recent pandemic COVID-19. Resiliency is followed by green technology to further conservation of natural resources and implementation of clean technology that may lead to increase the supply chain sustainability.

Table 8 explains cash management and capital accessibility as one of the crucial criteria. Capital accessibility for sustainable business becomes a critical issue and getting 


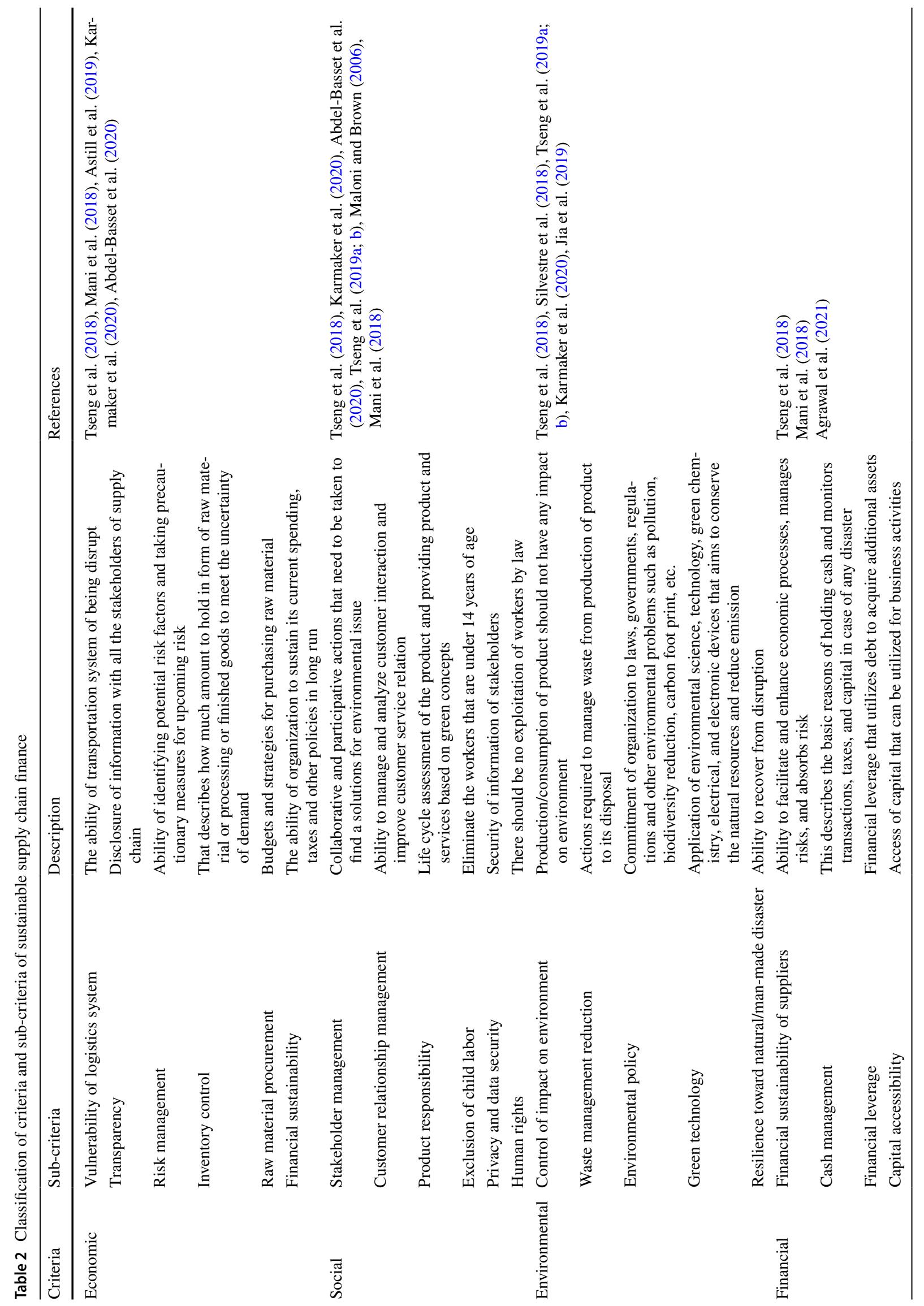


Table 3 Details of experts that responded for questionnaire

\begin{tabular}{lll}
\hline Designation & Working area & $\begin{array}{c}\text { Expe- } \\
\text { rience } \\
\text { (years) }\end{array}$ \\
\hline Professor & Supply chain management & 15 \\
General Manager & Finance & 23 \\
Production Manager & Supply chain & 10 \\
Assistant Manager & Food industry & 12 \\
Associate Professor & Production and operation manage- & 20 \\
Senior Engineer & ment & 15 \\
\hline
\end{tabular}

Table 4 Relative importance of sustainable criteria

\begin{tabular}{lll}
\hline Criteria & Weight & Normalized weight \\
\hline Environmental & 0.4421133 & 0.372763068 \\
Social & 0.3122641 & 0.163282124 \\
Economic & 0.0914143 & 0.177075001 \\
Financial & 0.340252 & 0.286879807 \\
\hline
\end{tabular}

Table 5 Social criteria relative weights

\begin{tabular}{lll}
\hline Criteria & Weight & Normalized weights \\
\hline Stakeholder management & 1.994631 & 0.020250716 \\
Customer relationship management & 4.268591 & 0.043337349 \\
Product responsibility & 7.602912 & 0.077189408 \\
Exclusion of child labor & 13.56133 & 0.137682923 \\
Privacy and data security & 22.3813 & 0.227228677 \\
Human rights & 48.68806 & 0.494310928 \\
\hline
\end{tabular}

Table 6 Economic criteria relative weights

\begin{tabular}{lcl}
\hline Criteria & Weights & Normalized weights \\
\hline Vulnerability of logistics & 1.540734 & 0.027165 \\
Transparency & 3.901815 & 0.068795 \\
Risk and crisis management & 9.580479 & 0.168918 \\
Inventory control & 17.24066 & 0.303979 \\
Raw material procurement & 24.45295 & 0.431142 \\
\hline
\end{tabular}

financed for this is such a big challenge. This also acts as a barrier for sustainable development.

\section{Results}

This study discusses about the criteria that are crucial for sustainable supply chain finance. Social values have been allotted maximum importance that aligns with the study performed by Mani et al. (2018). This study emphasizes the role of finance in achieving social values without harming environmental values as well. COVID-19 has harmed the social values of the organization badly. COVID has influenced these issues severely if we compare Pre-Covid. Study performed by Karmaker et al. (2020) in Post-COVID context also prioritizes employee safety and stakeholder management and their empowerment as most important drivers of sustainable supply chain. This study also analyzes the most crucial factors that may play an important role in re-configuring the supply chain as sustainable supply chain.

A study performed by Tseng et al. (2018), in Pre-COVID highlights that economic criteria are most crucial followed by social and environmental, respectively. But in this study, social criterion followed by environmental criteria has been allotted maximum weight that gives a view of transition toward adaption of social and environmental values in Post-COVID.

Jia et al. (2019) also reviewed the factors influencing the sustainable supply chain finance and considered social and financial criteria as main players in consideration of evolving sustainable supply chain.

\section{Theoretical and Managerial Implications}

The purpose of the efficient regulation of SSCF is to enhance the working capital level for both the suppliers and buyers. For this cash flow and its management play, a crucial role because it directly relates to finance leverage, capital accessibility, and financial stability of suppliers. These are all financial attributes that indirectly affect the total cash flow throughout the supply chain. These financial aspects have critical impact on improving SCF. Investment in green
Table 7 Social criteria relative weights

\begin{tabular}{lcc}
\hline Criteria & Weights & Normalized weights \\
\hline Control of impact on environment & 1.66842 & 0.030869965 \\
Waste management reduction & 4.022403 & 0.074424571 \\
Environmental policy & 7.8729871 & 0.145670061 \\
Green technology & 18.959922 & 0.350806236 \\
Resilience toward human/man-made disaster & 21.522975 & 0.398229167 \\
\hline
\end{tabular}


Table 8 Financial criteria relative weights

\begin{tabular}{lll}
\hline Criteria & Weights & Normalized weights \\
\hline $\begin{array}{l}\text { Financial sustainability of } \\
\text { suppliers }\end{array}$ & 1.27113942 & 0.05060576 \\
Cash management & 8.86739563 & 0.35302286 \\
Financial leverage & 7.14499482 & 0.28445178 \\
Capital accessibility & 7.83494443 & 0.3119196 \\
\hline
\end{tabular}

technology, environmental policy requires stability in terms of financial aspects to develop sustainable environment in organization. Social values of organization directly or indirectly depend upon financial stability of the organization. Financial attributes of supply chain play an incredible role in moving toward sustainable. Tseng et al. (2018) also discussed financial aspects of supply chain as the foundation for any further development. This study further reveals environmental aspects as second most important attribute for SSCF followed by social and economic. In conclusion, this research work contributes to enhancing knowledge of SSCF by investigating its decisive attributes, which offers greater insights for future research. This study provides evidence that financial and environmental attributes are two main criteria for decision-making regarding SSCF.

\section{Managerial Implications}

This study helps in identifying the critical aspects in terms of management. Cash management is one of the most important attributes, not only for financial aspects, but for all other criteria. Further inventory management, risk management, procurement management, stakeholder management, etc. are some of the important criteria that need to be considered while decision-making. Factors identified in this study can be further utilized for decision-making in organizations as well as future research studies.

\section{Conclusions}

This study a detailed explanation of sustainable supply chain is presented. Further we discussed how COVID-19 has enhanced the importance of sustainable supply chain. Here, we identified most critical drivers of sustainable supply chain along with their priority in context of food supply chain. This prioritization has been done with the help of MCDM technique that concludes that financial values of any organization are the most crucial criteria followed by environmental, social, and economic.
This study should also be performed to understand the inter-relationship among the criteria. Further study can be performed to explore the performance measures of sustainable supply chain finance. Researchers should also consider the influence of one criteria on another so that simultaneous impact can be analyzed.

This study does not include political factors, inter-organizational or external factors for decision-making. Psychological aspects of stakeholders and employees can also be included in further research. Along with this, here we have obtained the results by Fuzzy-AHP without any comparison to other methods. This work can be extended by applying different methodologies of MCDM.

\section{Key Questions Reflecting Applicability in Real Life}

a) What are the important factors of sustainable supply chain finance in real life environment?

b) How do these factors contribute in achieving sustainable development goals?

c) How COVID-19 has impacted SSCF and what are the challenges that have occurred due to COVID in achieving these SDGs?

d) What is the importance of different factors in terms of Sustainable Supply chain finance?

Acknowledgements The authors are acknowledged to the professionals for giving their response for the questionnaire related to sustainable supply chain finance. The authors are also grateful to the Editor-in Chief and reviewers for their comments and guidance that have helped in enhancing the quality of this paper.

Author contributions Only contributing authors are included in this research work.

Funding The authors declare that there is no funding involved with this research work.

Code availability With this, we declare that code is available on demand.

\section{Declarations}

Conflict of interest The authors declare there is no conflict of interest as well.

\section{References}

Abdel-Basset, M., Mohammad, R., Sallam, K., \& Elhoseny, M. (2020). A novel decision-making model for sustainable supply chain 
finance under uncertainty environment. Journal of Cleaner Production. https://doi.org/10.1016/j.jclepro.2020.122324.

Agrawal, S., Singh, P., \& Mazumdar, M. (2021). Innovation, firm size and ownership: A study of firm transition in India. International Journal of Global Business and Competitiveness, 16, 15-27. https://doi.org/10.1007/s42943-021-00022-y.

Arulraj, D. J., \& Annamalai, T. R. (2020). Firms' financing choices and firm productivity: Evidence from an emerging economy. International Journal of Global Business and Competitiveness, 15, 35-48. https://doi.org/10.1007/s42943-020-00008-2.

Astill, J., Dara, R. A., Campbell, M., Farber, J. M., Fraser, E. D. G., Sharif, S., \& Yada, R. Y. (2019). Transparency in food supply chains: A review of enabling technology solutions. Food Science and Technology, 91, 240-247. https://doi.org/10.1016/j. tifs.2019.07.024.

Awasthi, A., Govindan, K., \& Gold, S. (2018). Multi-tier sustainable global supplier selection using a fuzzy AHP-VIKOR based approach. International Journal of Production Economics, 195, 106-117. https://doi.org/10.1016/j.ijpe.2017.10.013.

Barrow, C. J. (2018). Sustainable development. The International Encyclopedia of Anthropology. https://doi.org/10.1002/97811 18924396.wbiea1463.

Biswas, T. K., Akash, S. M., \& Saha, S. (2018). A fuzzy-AHP method for selection best apparel item to start-up with new garment factory : A case study in Bangladesh. International Journal of Research in Industrial Engineering, 7(1), 32-50. https://doi.org/10.22105/riej.2018.111802.1034.

Brundtland, G. (1987). Report of the world commission on environment and development: Our common future. United Nations General Assembly document A/42/427.

Caldecott, B. (2020). Defining transition finance and embedding it in the post-Covid-19 recovery. Journal of Sustainable Finance and Investment. https://doi.org/10.1080/20430795.2020.1813478.

Cardenas, M., Ayala, J. J. G., \& Hernandez-Aguilera, J. H. (2020). Boosting ESG finance for the Post-COVID19 world. Centre on Global Energy Policy, SIPA.

Chang, D. (1996). Applications of the extent analysis method on fuzzy-AHP. European Journal of Operational Research, 95, 649-655.

Ferreira, M. C. R. D. C., Sobreiro, V. A., Kimura, H., \& Barboza, F. L. D. M. (2016). A systematic review of literature about finance and sustainability. Journal of Sustainable Finance \& Investment, 6(2), 112-147. https://doi.org/10.1080/20430795.2016. 1177438 .

Filho, W. L., Brandli, L. L., Salvia, A. M., Rayman-Bacchus, L., \& Platje, J. (2020). COVID-19 and the UN sustainable development goals: Threat to solidarity or an opportunity? Sustainability. https://doi.org/10.3390/su12135343.

Fortune. (2020). https://fortune.com/2020/02/21/fortune-1000-coron avirus-china-supplychain-impact/. Accessed 10 Mar 2020.

ILO. (2021). https://www.ilo.org/asia/media-centre/news/WCMS_ 763819/lang--en/index.html. Assessed 12 Jan 2021.

Jia, F., Zhang, T., \& Chen, L. (2019). Sustainable supply chain finance: Towards a research agenda. Journal of Cleaner Production. https://doi.org/10.1016/j.jclepro.2019.118680.
Karmaker, C. L., Ahmed, T., Ahmed, S., Ali, S. M., Moktadir, M. A., \& Kabir, G. (2020). Improving supply chain sustainability in the context of COVID-19 pandemic in an emerging economy: Exploring drivers using an integrated model. Sustainable Production and Comsumption. https://doi.org/10.1016/j.spc.2020. 09.019.

Laarhoven, P. J. M. V., \& Pedrycz, W. (1983). A fuzzy extension of Satty's priority theory. Fuzzy Sets and Systems, 11, 229-241.

Maloni, M. J., \& Brown, M. E. (2006). Corporate social responsibility in the supply chain: An application in the food industry. Journal of Business Ethics, 68, 35-52. https://doi.org/10.1007/ s10551-006-9038-0.

Mani, V., Gunasekaran, A., \& Delgado, C. (2018). Supply chain social sustainability: Standard adopted practices in Portuguese manufacturing firms. International Journal of Production Economics, 198, 149-164. https://doi.org/10.1016/j.ijpe.2018.01. 032.

OCED. (2021). https://www.oecd.org/economic-outlook/. Assessed 12 Jan 2021.

Runde, D. F., Metzger, C., \& Abdullah, H. F. (2020). Covid-19 demands innovative ideas for financing the SDGs. Center for Strategic and International Studies. https://www.jstor.org/stable/ resrep24770.

Saaty. (1980). The analytic hierarchy process. McGraw-Hill.

Schoenmaker, D. (2019). A framework for sustainable finance. https://doi.org/10.2139/ssrn.3125351.

Sharma, M., Luthra, S., Joshi, S., \& Kumar, A. (2020). Developing a framework for enhancing survivability of sustainable supply chains during and post-COVID-19 pandemic. International Journal of Logistics Research and Applications. https://doi. org/10.1080/13675567.2020.1810213.

Silvestre, B. S. (2015). Sustainable supply chain management in emerging economies: Environmental turbulence, institutional voids and sustainability trajectories. International Journal of Production Economics, 167, 156-169. https://doi.org/10.1016/j. ijpe.2015.05.025.

Silvestre, M. L. D., Gallo, P., Ippolito, M. G., Sanseverino, E. R., \& Zizzo, G. (2018). A technical approach to the energy blockchain in microgrids. IEEE Transactions on Industrial Informatics, 14(11), 4792-4803.

Tseng, M., Lim, M. K., \& Wu, K. (2019a). Improving the benefits and costs on sustainable supply chain finance under uncertainty. International Journal of Production Economics. https://doi.org/ 10.1016/j.ijpe.2019.06.017.

Tseng, M., Tan, P. A., Jeng, S., Lin, C. R., Nehash, Y. T., \& Darsono, S. N. A. C. (2019b). Sustainable investment: Integrated among corporate governance, economic performance and market risks using investor preference approach. Sustainability. https://doi. org/10.3390/su11072108.

Tseng, M., Wu, K., Hu, J., \& Wang, C. (2018). Decision making model for sustainable supply chain finance under uncertainties. International Journal of Production Economics, 205, 30-36. https://doi.org/10.1016/j.ijpe.2018.08.024. 


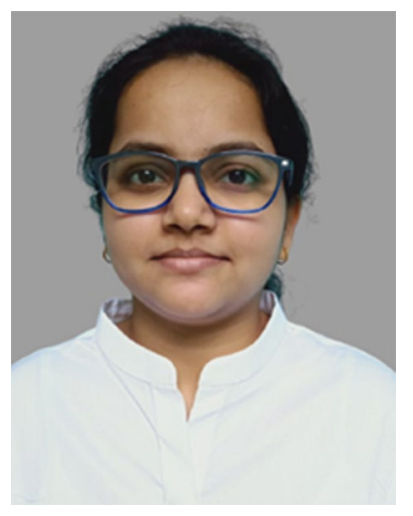

Nainsi Gupta is pursuing Master's in Industrial Engineering from MNIT Jaipur. She has completed her graduation from Govind Ballabh Pant Engineering College, Pauri Garhwal in Production Engineering. She has research interest in supply chain and sustainability. ORCID: h t t p s : / / or cid. org / 0000-0001-6686-1442

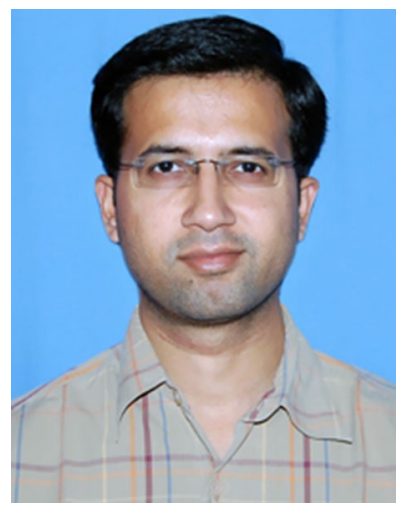

Gunjan Soni did his B.E. from University of Rajasthan, M.Tech from IIT-Delhi and $\mathrm{PhD}$. from Birla Institute of Technology and Science, Pilani in 2012. He is working as an Assistant Professor in Malaviya National Institute of Technology, Jaipur, Rajasthan, India. He has over 15 years teaching experience at under graduate and graduate levels. His areas of research interest are Predictive maintenance and Digital technology applications in supply chain management. He has published more than 80 papers in peer reviewed journals including IEEE Transactions on Engineering Management, Production Planning and Control, Annals of Operations Research, Computers and Industrial Engineering etc. ORCID: https://orcid.org/0000-0001-8182-3743 